\title{
Efficiency of the primary health care policy in Brazilian municipalities: an application of the Pearl's Structural Causal Model
}

\section{A eficiência da política de atenção básica de saúde nos municípios brasileiros: uma aplicação do Modelo Causal Estrutural de Pearl}

\author{
Darlan Christiano Kroth' ${ }^{1}$, Raquel Rangel de Meirelles Guimarães ${ }^{2}$ (D) \\ 'Universidade Federal da Fronteira Sul (UFFS) - Chapecó (SC), Brasil. \\ ${ }^{2}$ Universidade Federal do Paraná (UFPR) - Curitiba (PR), Brasil.
}

How to cite: Kroth DC, Guimarães RRM. Efficiency of the primary health care policy in Brazilian municipalities: an application of the Pearl's Structural Causal Model. Cad Saúde Colet, 2021;29(esp.):16-27. https://doi.org/10.1590/1414$462 \times 202199010297$

\begin{abstract}
Background: In recent years, public health policies and their effects on improving health outcomes have been gaining prominence in the economic literature and on the agenda of international organizations. Objective: This study aims to evaluate the causal effect of the "Pacto pela Saúde" (Pact for Health) program on health policy performance in terms of a Health Vulnerability Index $(\mathrm{HVI})$ of Brazilian municipalities from 2006 to 2013. The "Pacto pela Saúde" program is the current operational standard of the Brazilian Unified Health System (SUS). One of the main guidelines of this program was to improve health policy governance. Method:The effect resulting from efficiency gains of the participation of municipalities in the health policy on the HVI was estimated by the Pearl's Structural Causal Model. Results: The results indicate a positive and significant impact of efficiency management on the reduction of health vulnerability in the municipalities. The Pearl's Causal Model and the back-door criterion of causal identification were employed to calculate the effects of the "Pacto pela Saúde" program on the HVI. Conclusion: The use of Pearl's method in this study contributed to a more comprehensive analysis of the effects of the "Pacto pela Saúde" program on health outcomes and, therefore, its use in future research on the analysis of public policies is recommended.
\end{abstract}

Keywords: health policy; primary health care; Pearl's Causal Model; dose-response function.

\section{RESUMO}

Introdução: A condução da política de saúde pública e seus efeitos sobre a melhoria dos resultados de saúde vêm ganhando destaque nos últimos anos na literatura econômica e na agenda dos organismos internacionais. Objetivo: Avaliar o efeito causal do Pacto pela Saúde sobre o desempenho da política de saúde, em termos de um indicador de vulnerabilidade de saúde (IVS), dos municípios brasileiros no período de 2006 a 2013. O Pacto pela Saúde é a norma operacional vigente pelo Sistema Único de Saúde (SUS) do Brasil e teve como uma de suas principais diretrizes o aprimoramento da governança da política de saúde. Método: A estimação do efeito causal decorrente dos ganhos de eficiência da participação do município na política sobre o IVS se deu por meio do Modelo Causal Estrutural (MCE) de Pearl. Resultados: Houve a estimação de um impacto positivo e significante da eficiência da gestão sobre a queda da vulnerabilidade de saúde dos municípios e a adequação do MCE e do critério back-door de Pearl de identificação causal com o cálculo do efeito do Pacto pela Saúde sobre o IVS. Conclusão: A utilização do método de Pearl contribuiu para uma análise mais adequada do efeito do Pacto pela Saúde sobre os IVS, e, portanto, recomenda-se sua utilização em estudos futuros de análise de políticas públicas. Palavras-chave: política de saúde; atenção primária à saúde; Modelo Causal de Pearl; função doseresposta.

Study carried out at Universidade Federal do Paraná (UFPR) - Curitiba (PR), Brasil.

Correspondence: Darlan Christiano Kroth. E-mail: dckroth@uffs.edu.br

Financial support: none.

Conflict of interests: nothing to declare.

Received on: July 22, 2019. Accepted on: Nov. 21, 2019
This is an Open Access article distributed under the terms of the Creative Commons Attribution License, which permits unrestricted use, distribution, and reproduction in any medium, provided the original work is properly cited. 


\section{INTRODUCTION}

In recent years, public health policies and their effects on improving health outcomes have been gaining prominence in the economic literature and on the agenda of international organizations ${ }^{1-6}$. The chief relevance of this theme stems, on the one hand, from the understanding that health is a primordial input to guarantee economic development since it is a part of human capital ${ }^{7}$ and, on the other hand, from the understanding that changes associated with population demographics (population aging), disease epidemiology (higher incidence of chronic and degenerative diseases), and costs of medical technology impact on health expenses worldwide ${ }^{8,9}$.

Therefore, there is need (and relevance) to evaluate the best way to promote public health while ensuring both better health outcomes and lower production costs. In short, researchers and policymakers should be concerned about how to make health systems more efficient.

The literature highlights two central elements that contribute to improving the efficiency of health systems ${ }^{4,5,10}$.

Health production technology, that is, how health services are provided to the population, is the first central element. According to Starfield and Shi ${ }^{11}$ and Solla and Chioro' ${ }^{12}$, primary health care (PHC) ${ }^{1}$ can be the most cost-efficient model. Its advantage over other assistance models is due to its emphasis on health-promoting practices that address social determinants of health. In addition, $\mathrm{PHC}$ operates as the users' first contact or preferred entrance to the health system. This means that the $\mathrm{PHC}$ model is the starting point of attention and a filter for access to specialized services. In PHC, health services are provided by community-oriented family physicians who are aware of the population's health needs based on their economic and social context and follow up on their patients over time ${ }^{13,14}$.

These characteristics of PHC contribute to increasing the resolution capacity and lower cost of this model. As acknowledged by Starfield ${ }^{13}$, when health promotion is directly focused, individuals receive better guidance on health care and education, which makes them more capable of taking care of their own health and that of their families, thus reducing the demand for treatment in health care centers. The presence of family physicians who follow up the individuals longitudinally in a given region enables more accurate diagnoses of their health statuses and, therefore, more appropriate treatments. This avoids redundant and/or unnecessary procedure prescriptions, such as exams, medications, and surgeries ${ }^{5,15}$.

The second element of efficiency is related to health governance, which includes actions of formulating and coordinating public health policies, allocating resources, managing and planning the delivery of health services, and regulating / monitoring health systems. The World Health Organization (WHO) ${ }^{4}$ states that improved governance contributes to increased health production factors that enable health systems to expand their supply and resolution of health services, and thus become more cost-efficient in terms of health outcomes.

Studies addressing the effect of health policy governance on health indicators have demonstrated that health expenditures improve health indicators in countries with good governance. This governance is considered good in countries where budget formulation, implementation, and monitoring are effective ${ }^{16}$, and the sustainability of health expenditure does not compromise the delivery of services as long as appropriate policy instruments are adopted ${ }^{17}$.

Currently, one of the most widely used instruments of governance in the area of public health is decentralization. Decentralization refers to the transfer of power and authority to subnational or local levels of government in the provision of health services to that locality. Because local governments are closer to and know the preferences (habits and local culture) of the population, and thus can process information and knowledge concerning local health

\footnotetext{
The definition of Primary Health Care $(\mathrm{PHC})$ used in this study is in line with the proposal from the First International Conference on Primary Health Care held in Alma-Ata, Kazakhstan (former USSR) in 1978, which was a watershed event in the political defense of this health care model.
} 
issues more rapidly, they are able to expand the services offered at a relatively lower $\operatorname{cost}^{18}$. It is also recognized that decentralization in health has some limitations. The potential inefficiency factors of health decentralization are found in Saltman ${ }^{18}$, a review that meets the so-called second generation of decentralization studies ${ }^{19}$. Empirical research evaluating the impact of decentralization on health outcomes underpins its positive effects ${ }^{20,21}$.

In the Brazilian context, the Unified Health System (SUS) has been consolidating the operationalization of a comprehensive system (universal, integral, and decentralized) since its institutionalization in 1988. SUS also has increased efficiency as one of the main goals to improve its health policy. In its recent history, two movements of the national health policy to improve the system efficiency can be observed: (a) decentralization of resources to the Federation units (states) and (b) focus on PHC, considering that the municipalities are responsible for the provision of these services in the country. Therefore, the movement carried out by SUS to improve the system efficiency is in line with the aforementioned international guidelines.

In 2006, the Brazilian government launched a new legal framework for SUS called "Pacto pela Saúde" (Pact for Health) (Brazilian Ministry of Health (MS), Ordinance no. 399/2006), which stressed the improvement of health policy governance by the states, with special attention to management by results, formalized in a Term of Management Commitment (TMC). By agreeing with and signing the TMC, the municipality committed itself to improving the supply of services (PHC) and achieving the nationally established health indicators ${ }^{22}$.

The TMCs, regulated by Ordinance no. 699/2006 of the MS, are documents that formalize the "Pacto pela Saúde" program among municipalities. In other words, they are aimed at instituting the commitment to responsibilities and attributions inherent in governmental spheres in the governance of the health system. They comprise the objectives, goals, and monitoring and evaluation indicators established in reference to national and state priorities, which are negotiated between the municipalities under various instances of SUS ${ }^{22}$. From these priorities, the municipalities plan their own goals, which must be approved by the Municipal Health Councils and be included in the Municipal Health Plans. The goals are developed considering the health circumstances of each municipality.

This management policy via TMC was in force from 2006 to 2012, and was adopted by 4,587 (82\%) Brazilian municipalities. In this context, the "Pacto pela Saúde" 'program was an important mechanism to ensure the efficiency and effectiveness of the health policy by focusing on PHC and strengthening enforcement mechanisms through goal setting. A study conducted by Kroth and Guimarães ${ }^{23}$ evaluated the causal effect of the "Pacto pela Saúde" program on an efficiency management indicator using an econometric model of dose-response with generalized propensity score. The main results found by those authors showed that the adherence time to the "Pacto pela Saúde" program positively and significantly impacted on the levels of efficiency of the PHC policy in the participating municipalities. These results corroborate the importance of governance for improving the efficiency of SUS.

Empirical studies addressing the effects of health policy with an emphasis on PHC are still scarce in Brazil, especially with large sample sizes (number of municipalities). Such studies do not incorporate structural models, and thus do not consider aspects of health system management ${ }^{36}$.

This study seeks to address this literature gap by evaluating the causal effect of the "Pacto pela Saúde" program on health outcomes. Therefore, its main objective is to assess how efficiency gains contribute to improve health outcomes in Brazilian municipalities. Specifically, it tries to answer the following question: Did the improvement of the municipal health policy management efficiency provided by adherence to the "Pacto pela Saúde" program have a positive impact on the Health Vulnerability Index $(\mathrm{HVI})$ in the participating municipalities?

In order to reach the proposed objective and answer the research question, this study was divided into three stages. In the first stage, a Structural Causal Model (SCM) of the Brazilian municipal health policy and the back-door criterion for causal effect identification were developed $^{24}$. In the second stage, an HVI was constructed based on indicators of mortality 
and morbidity sensitive to PHC, and the principal components analysis (PCA) technique was used. In the third stage, the econometric estimation of the SCM was performed through a dose-response function with generalized propensity score $\mathrm{s}^{25,26}$.

This study contributes to the literature by i) analyzing, in a pioneering and rigorous way, the causal impact of the "Pacto pela Saúde" program; ii) providing substantial evidence on how municipal health production responds to this policy; iii) calculating a specific municipal HVI for PHC.

\section{METHOD}

The present study adopted a set of methods from the literature on economic evaluation of public policies ${ }^{27}$. Specifically, a structural causal mode ${ }^{24}$ (henceforth, $\mathrm{SCM}$ ) of health policy in Brazilian municipalities was constructed. A chain of results was created to develop this model. Glennerster and Takavarasha ${ }^{28}$ defined a results chain as a tool that describes the path through which impacts are reached, or the causal logic from the beginning to the end of a policy. This tool starts from the resources available aiming to reach long-term goals. From the results chain, a multivariate Principal Components Analysis (PCA) technique was used to develop an HVI based on indicators of mortality and morbidity that are sensitive to PHC.

With the SCM, the back-door criterion for identification of the causal effect was developed, and an impact evaluation of the policy HVI was estimated using an econometric model of dose-response with generalized propensity score ${ }^{25,26}$. This method enables identification of the causal effect of the policy considering peculiarities of observational data such as non-random attribution of the treatment group, that is, the set of units (municipalities) attended by the policy.

In summary, this study was developed in three stages: preparation of the SCM and application of the back-door criterion, construction of the $\mathrm{HVI}$, and econometric estimation via the dose-response function.

\section{Health Vulnerability Index (HVI) of Brazilian municipalities}

Measurement of the HVI in Brazilian municipalities was based on information from the Health Information System of the MS ${ }^{22}$. This system includes a database of 52 variables related to PHC and information about mortality and live births. From this database, the variables that could express the PHC performance were selected, as specified by Starfield and Chi ${ }^{11}$. Availability of data for all municipalities according to every year of the "Pacto pela Saúde" program and the variance of information between the municipalities were the other criteria considered. After that, the indicator was calculated using the PCA methodology, and the calculated components were weighed according to the method proposed by Jolifee ${ }^{29}$. From the weighed calculation, the indicator for each municipality and year was calculated in conformity with the following Equation 1:

$$
H V I_{i}=\sigma_{1} A_{1 i}+\sigma_{2} A_{2 i}+\sigma_{3} A_{3 i}+\sigma_{4} A_{4 i}+\sigma_{5} A_{5 i}
$$

where, $\mathrm{A}_{1 \mathrm{i}}$ is the health variable that comprises the PCA of the HVI of municipality 1 and $\sigma$ is the weight calculated by the PCA.

From these criteria, five variables belonging to the HVI were identified for 5,397 municipalities: i) deaths due to preventable causes in children aged $<5$ years per 1,000 inhabitants; ii) number of hospitalizations owing to conditions sensitive to PHC per 1,000 inhabitants; iii) number of low-birth-weight live births $(<2,500 \mathrm{~g})$ per 1,000 live births with weight measurement; iv) undernourished children under one year old per 1,000 children under one year old; v) number of hospitalizations due to pneumonia and dehydration in children aged $<5$ years per 1,000 inhabitants. The HVI varies from zero to one, where values closer to zero indicate lower health vulnerability of the municipality. 


\section{RESULTS}

\section{The structural causal model (SCM) of Brazilian municipal health policy}

The SCM preparation proposed by Pearl ${ }^{24}$ was based on the literature on health policy governance and social determinants of health under the $\mathrm{PHC}$ model ${ }^{3,4,10,30}$. Thus, the model was constructed aiming to map the determinants of health outcomes in Brazilian municipalities and enable identification of the total causal effect of the efficiency of health policy management on health outcomes.

The system of Equations 2, which is composed of 14 equations, presents the SCM. These equations represent how the explanatory variables of health outcomes are determined. Figure 1 depicts the causal diagram associated with the SCM of Equation 2, which considers the connections between these variables in the model, as recommended by Pearl ${ }^{24}$.

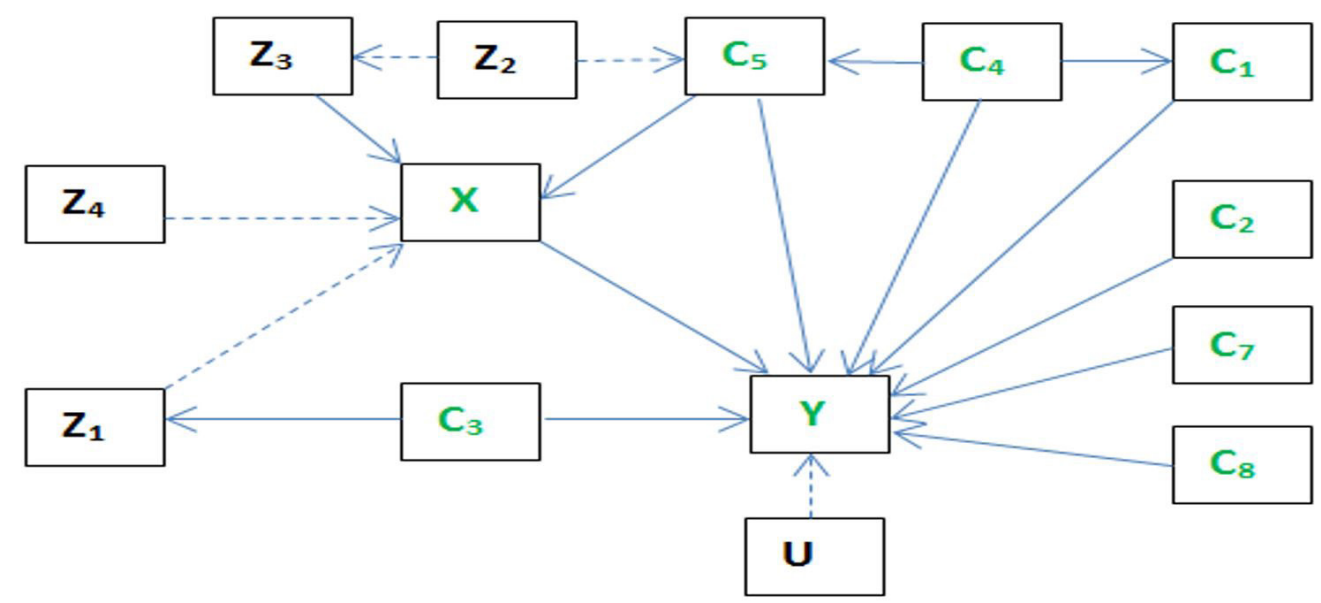

Figure 1. Diagram associated with the Structural Equation Model 2, which delineates the impact of municipal health policy on health vulnerability. Source: Prepared by the authors. Note: The error terms of the equations were suppressed due to lack of space, except for the equation of health outcomes $(Y)$

$Y=f\left(X, C_{1}, C_{2}, C_{3}, C_{4}, C_{5}, C_{6}, C_{7}, U\right)$

$X=g\left(Z_{1}, Z_{3}, Z_{4}, C_{5}, U^{\prime}\right)$

$C_{1}=f_{1}\left(C_{4}, U_{1}\right)$

$C_{2}=f_{2}\left(U_{2}\right)$

$C_{3}=f_{3}\left(U_{3}\right)$

$C_{4}=f_{4}\left(U_{4}\right)$

$C_{5}=f_{5}\left(C_{4}, Z_{2}, U_{5}\right)$

$C_{6}=f_{7}\left(U_{7}\right)$

$C_{7}=f_{8}\left(U_{8}\right)$ 


$$
\begin{aligned}
& Z_{1}=g_{1}\left(C_{3}, U_{1}^{\prime}\right) \\
& Z_{2}=g_{2}\left(U_{2}^{\prime}\right) \\
& Z_{3}=g_{3}\left(Z_{2}, U_{3}^{\prime}\right) \\
& Z_{4}=g_{4}\left(U_{4}^{\prime}\right)
\end{aligned}
$$

where: Y: municipality health outcome, represented by the HVl; $\mathrm{X}$ : level of municipal health management efficiency, represented by the efficiency indicator; $C_{1}$ : sewage network in the municipality; $C_{2}$ : access to treated water in the municipality; $C_{3}$ : average schooling of the municipality's population; $C_{4}$ : gross domestic product (GDP) per capita of the municipality; $C_{5}$ : financial resources for the municipality's health sector; $C_{6}$ : proportion of children (aged 0-4 years) in relation to the municipality's total population; $C_{7}$ : proportion of older people (aged $\geq 65$ years) in relation to the municipality's total population; $Z_{1}$ : effectiveness of social control and monitoring of health policies (Municipal Health Council, Courts of Accounts); $Z_{2}$ : Municipal Administration's sensitivity and commitment to the health policy; $Z_{3}$ : health professionals; $Z_{4}$ : technical capacity of the Secretary of Health; f's and g's: unknown arbitrary function; $U$ : exogenous variable (error term).

Equation 2 underpinned the relationship between associated factors and health outcome, henceforth denoted by Y. In this way, considering the literature and functioning of the phenomena, $\mathrm{Y}$ is shown to be a direct function of at least nine other variables. Management efficiency (represented by an efficiency indicator) or health policy governance is able to improve municipality health outcomes as it carries out an adequate planning of actions and optimizes health resources to promote health to the population $3,4,10,20$.

In addition, variables representative of the municipal basic sanitation $\left(C_{1}\right.$ and $\left.C_{2}\right)$ consensually under health improvisations in the literature on health economics - are also linked to the literature on social determinants of health, according to Dahlgren and Whitehead ${ }^{31}$ and Wilkinson and Marmot $^{30}$. In these terms, municipalities that have adequate basic sanitation networks avoid the spreading several diseases.

Human capital $\left(C_{3}\right)$ is responsible for making people more adept at producing health and leaning healthy habits, e.g., balanced diet, physical exercise, and absence of addictions, such as smoking. It is expected that municipalities with higher education levels have lower health vulnerability ${ }^{32}$. GDP per capita $\left(C_{4}\right)$ represents the economic dynamics of the municipality and, therefore, municipalities with higher GDP per capita are more likely to gather financial resources to invest on health, thus promoting better health conditions and preventing diseases ${ }^{5}$.

Health financial resources $\left(C_{5}\right)$, though dependent on the economic dynamics of the municipality, may take a larger portion of the municipal budget. This larger budget can make the course of actions proposed in the municipal health policy feasible ${ }^{4,20}$.

Finally, there are variables that can be considered independent of the policy governance, but which have a great impact on health outcomes. For instance, the relative participation of certain population groups in municipalities $\left(C_{6}\right.$ and $\left.C_{7}\right)$ is more susceptible / likely to receive health care ${ }^{5}$. In addition, the individuals' behavior may directly influence their health status $s^{32,33}$, and genetic factors are other unobserved factors $(U)$ that could be included and interfere in the HVI of the municipalities.

Considering the aforementioned explanations, it can be asserted that the efficiency factor of management $(X)$ is diluted among other relevant factors that determine health outcomes. This demonstrates that improving the efficiency of health policy management by itself does not guarantee an improvement in the HVI. To illustrate this conclusion, Figure 1 shows that management efficiency affects health outcomes directly (unidirectional arrow from $X$ to $Y$ ), but on the other hand, it is influenced by four factors: social control $\left(Z_{1}\right)$, technical training of the Municipal Health Secretary $\left(Z_{4}\right)$, health professionals $\left(Z_{3}\right)$, and health budget $\left(C_{5}\right)$. Hence, 
a municipal health policy (in the case of the "Pacto pela Saúde" program) could contribute to improving the efficiency of health management by promoting / encouraging one of these four factors.

Along these lines, the structural model elucidates that health policy has the potential to impact the effective management of PHC services. As a result, this efficiency can contribute to improving health outcomes. However, this mechanism is not enough. As the health of the population depends on other factors that should be subsumed by other public policies, a health policy could contemplate multi- and inter-disciplinary actions to generate greater impact on health outcomes.

After preparation of the SCM and its associated diagram, the strategy to identify the total causal effect was developed - known as Pearl's back-door criterion ${ }^{24}$. This strategy was one of the steps taken prior to calculating the impact of the municipal health policy efficiency gains on HIV provided by the "Pacto pela Saúde" program. The back-door strategy was implemented in two steps, as suggested by Morgan and Winship ${ }^{34}$ : i) the first step determined the back-door trajectories revealed in Figure 1 (trajectories from $X$ to $Y$ ). There are five trajectories: $a$ ) $X \leftarrow Z_{1} \leftarrow$ $C_{3} \rightarrow Y$; b) $X \leftarrow C_{5} \rightarrow Y$; c) $X \leftarrow C_{5} \leftarrow C_{4} \rightarrow Y$; d) $X \leftarrow Z_{3} \leftarrow Z_{2} \rightarrow C_{5} \leftarrow C_{4} \rightarrow Y$; e) $X \leftarrow C_{5} \leftarrow C_{4} \rightarrow C_{1}$ $\rightarrow Y$; ii) the second step evaluated the existence of a collider (or endogenous) variable, which should be excluded. From this perspective, the variable $\mathrm{C} 5$ fits this definition and is excluded. At the conclusion of the two steps, and through the back-door criterion of identification of the causal effect, four conditioning variables are reached: C3, C4, Z3, and C1.

\section{Results of the estimation of the structural causal econometric model via the dose-response function}

In this section, the results of the structural causal model are presented as described in Equation 2. The objective of this estimation was to verify the total causal impact of health policy efficiency on Brazilian municipalities' health outcomes, represented by their HVI. To this end, the Pearl's back-door criterion was used as the identification strategy.

The policy intervention, provided by the "Pacto pela Saúde" program, is shown in Figure 2. The "Pacto pela Saúde" program is represented by the "do $\left(X=x^{\prime}\right)$ "operator. The inclusion of this operator intends to demonstrate where the intervention is carried out in the model and the impact channel of the policy, isolating it from other factors that influence the policy. Due to the intervention, equation system 2 undergoes a small variation, where equation $\mathrm{X}$ becomes $\mathrm{X}=\mathrm{x}$.

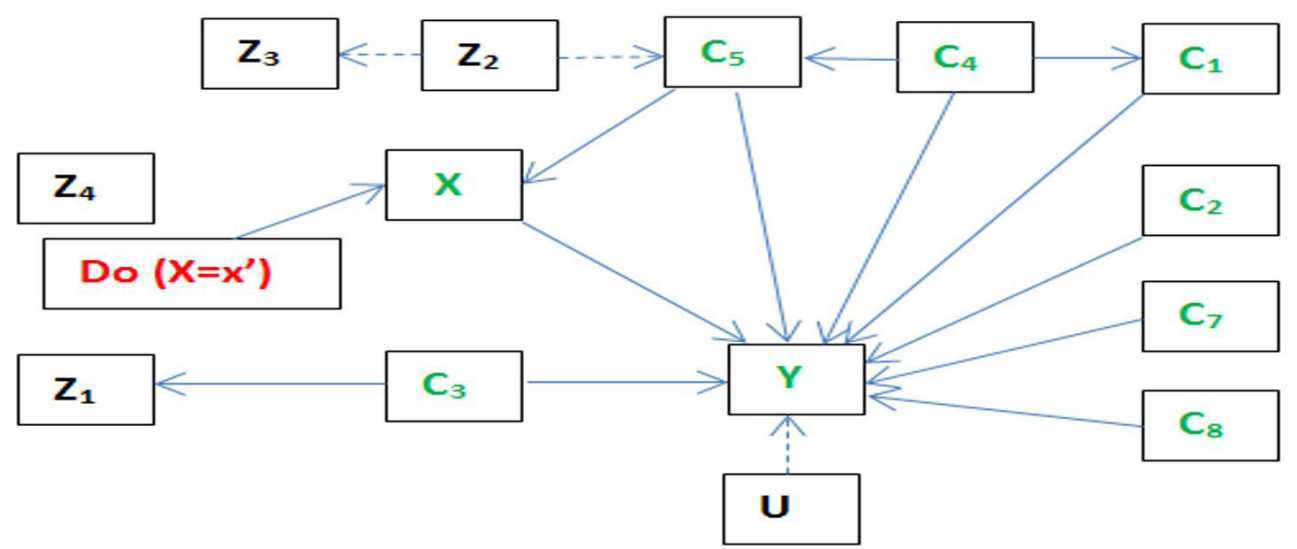

Figure 2. Diagram associated with the Modified Structural Model Mx of Equation 2, representing the Intervention $\mathrm{Do}\left(\mathrm{X}=\mathrm{x}^{\prime}\right)$. Source: Prepared by the authors

The econometric regression shows that, in the dose-response model, two regressions are estimated. The first regression provides a generalized propensity score (GPS), where the dependent variable is the time under the policy (DOSE) and the explanatory variables are 
indicators associated with the probability of participating for a certain time in the policy. In this way, the GPS regression is a Poisson's regression, since the dependent variable (DOSE) represents the time in years under the policy, which is characteristic of the variable for counting data. Table 1 shows the generalized propensity score coefficients for two versions of the HVI and their models.

Table 1. Coefficients of the generalized propensity score considering a Poisson's distribution

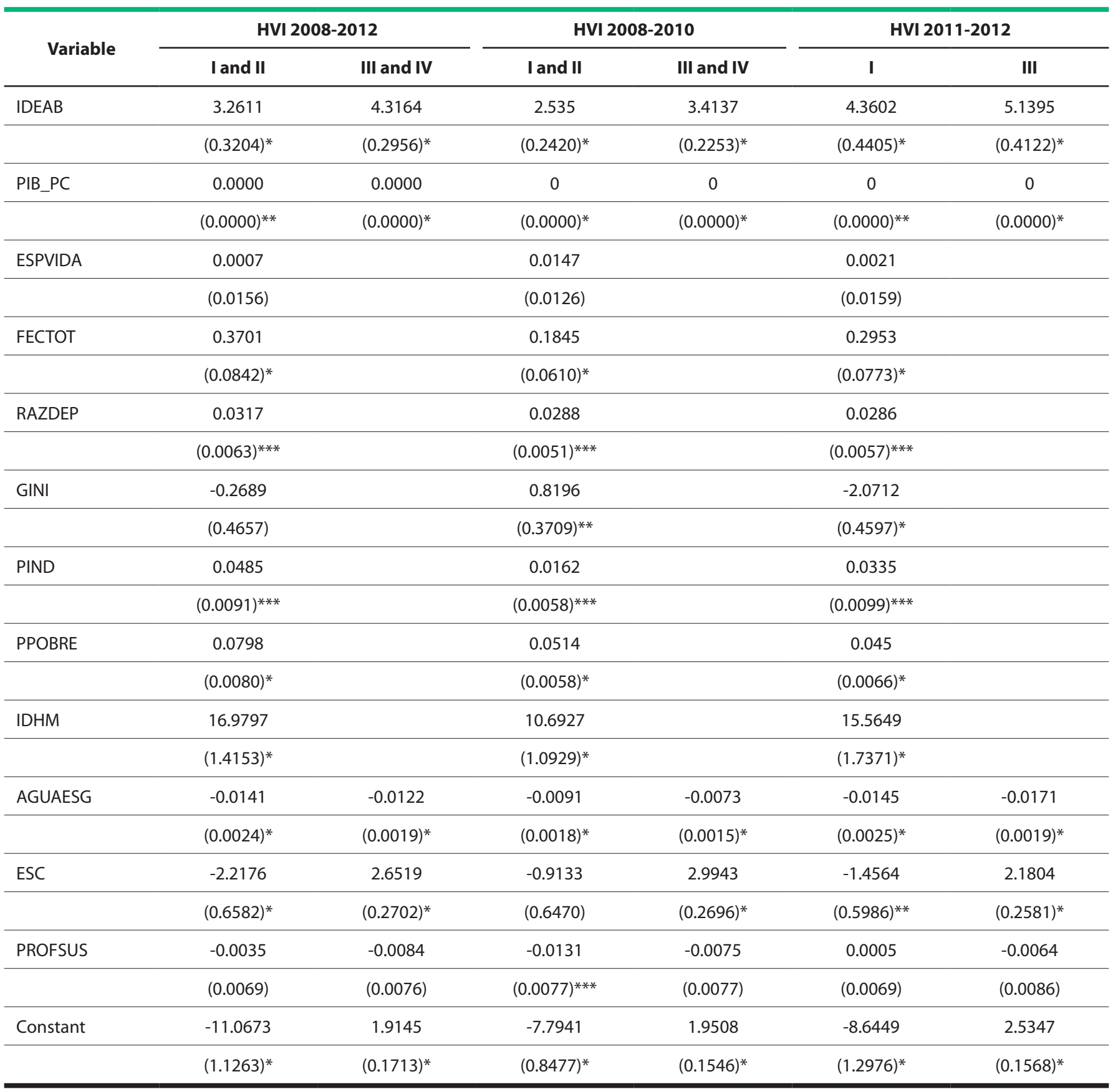

Notes: 1. Robust standard deviation (SD) in parentheses. 2. ${ }^{* * *}$ Significant at $1 \% ; *$ Significant at $5 \%$; ${ }^{*}$ Significant at $10 \%$. 3. IDEAB $=$ Efficiency indicator of municipal health policy management; PIB_PC = GDP per capita; ESPVIDA = Life expectancy at birth; FECTOT = total fertility rate; RAZDEP = Reason for dependency $(\%$ of pop. $<15$ and at 65 years and over pop, 15 to 64 years); GINI = Gini index; PIND = \% of extremely poor in pop. (p.c. income <USD 40 in 2010); PPOBRE = Percentage of poor in pop. (p.c. income <USD 80 in 2010); IDHM = Municipal Human Development Index; AGUAESG = Percentage of households with inadequate water and sewage network; ESC = Education (\% of pop. $>18$ years with 8 years of education); PROFSUS = Professionals of the Health Area - SUS per one 1,000 inhabitants. Source: Search results 
Subsequently, a regression, called dose-response, estimates the impact of time under the program (DOSE) on the response (HVI), and matches the generalized propensity score (GPS). Since in the second equation the dependent variable is the HVI (continuous indicator ranging from 0 to 1), a generalized linear model (GLM) was estimated by using a quasi-maximum likelihood estimator ${ }^{35}$. The estimation results of the dose-response function with generalized propensity score matching are shown in Table 2.

Table 2. Results of the Dose-Response Model. Health Vulnerability Index (HVI) is the dependent variable

\begin{tabular}{|c|c|c|c|c|}
\hline \multirow{2}{*}{$\begin{array}{l}\text { Independent variables } \\
\text { Time (years) in the Program }\end{array}$} & \multicolumn{2}{|c|}{ Average HVI 2008-2012 } & \multicolumn{2}{|c|}{ Average HVI 2008-2012 } \\
\hline & -0.0022 & -0.0020 & -0.0023 & -0.0021 \\
\hline \multirow[t]{2}{*}{ GPS (Pearl's variables following the back-door criterion) } & & 0.0636 & & 0.0658 \\
\hline & & $(0.0636)^{* * *}$ & & $(0.0122)^{* * *}$ \\
\hline GPS based on several confounders & $(0.0131)^{* * *}$ & & $(0.0128)^{* * * *}$ & \\
\hline \multirow[t]{2}{*}{ Constant } & 0.0457 & 0.0390 & 0.0454 & 0.0392 \\
\hline & $(0.0026)^{* * *}$ & $(0.0025)^{* * *}$ & $(0.0025)^{* * *}$ & $(0.0024)^{* * *}$ \\
\hline R2 & 0.0206 & 0.0208 & 0.0218 & 0.0216 \\
\hline R2 - adjust & 0.0201 & 0.0204 & 0.0214 & 0.0211 \\
\hline Root MSE & 0.0290 & 0.0276 & 0.0290 & 0.0276 \\
\hline
\end{tabular}

***Significant at 1\%; Source: Results of the research

To test robustness of the results, variants of the generalized propensity score model were estimated. Two versions of the pre-treatment variables and two versions of the dependent variable were considered. The scores were obtained based on the mean and median of the HVI for the 2008-2012 period, in a total of four estimated model versions, as summarized in Box 1. In all these versions, the impact variable is the time in years that a municipality remained in the "Pacto pela Saúde" program, or the number of years after signing the TMC. In this way, the municipalities fit into one of seven treatment groups: one year of adherence, two years of adherence, and so on.

Box 1. Variable specifications. Dose-response model with generalized propensity score for the impact of the "Pacto pela Saúde" program on HVI

\begin{tabular}{|cll|}
\hline Version & \multicolumn{1}{c|}{ Generalized propensity score } & Dose-response function \\
\hline Model I & $\begin{array}{l}\text { Pretreatment variables corresponding to the mean of the values observed in the } \\
\text { Demographic Censuses of } 2000 \text { and } 2010 \text { (IBGE). }\end{array}$ & Average HVI from 2008 to 2012. \\
\hline Model II & $\begin{array}{l}\text { Pretreatment variables corresponding to the mean of the values observed in the } \\
\text { Demographic Censuses of } 2000 \text { and } 2010 \text { (IBGE). }\end{array}$ & Median HVI from 2008 to 2012. \\
\hline Model III & Covariates that meet the back-door criterion. & Average HVI from 2008 to 2012. \\
\hline Model IV & Covariates that meet the back-door criterion. & Median HVI from 2008 to 2012. \\
\hline
\end{tabular}

Source: Prepared by the authors 
Substantively, the results show that an increase of one year in the time adhered to the "Pacto pela Saúde" program decreased the HVI during the 2008-2012 period in approximately -0.0020 and -0.0023 municipalities. Due to longer time in the program, it is concluded that the effect of commitment to target by means of the "Pacto pela Saúde" program caused a small but statistically significant reduction in the health vulnerability of the participating municipalities, as controlled by the PHC policy efficiency. Therefore, the longer the time of adherence to the program, the better the population's health as measured by the indicator.

\section{DISCUSSION}

Taken as a whole, it can be pointed out that "Pacto pela Saúde" program, by stimulating a more efficient management of $\mathrm{PHC}$ services, caused a reduction in the $\mathrm{HVI}$ of the participating municipalities between 2008 and 2012, being controlled by the efficiency of the PHC policy and other confounding factors. In this section, some channels that explain this causal effect are specified:

1) Commitment to goals and targets established among the Federation units (states) encouraged municipal administrations to take better health actions in order to reach results within the stipulated period. In addition, it was also possible to expand health policy governance through the coordination and control of the actions foreseen by the health plans;

2) Planning and coordination of health actions imposed the need for greater expenses and investments in the area of $\mathrm{PHC}$, such as the expansion and training of family health teams or community agents. It is noteworthy that there was an improvement in the financing and infrastructure indicators during the "Pacto pela Saúde" program validity period;

3) Expected results on improving management efficiency begin to consolidate only when municipalities reach a minimum number of years of adherence to the policy (or experience on management by results). Kroth and Guimarães ${ }^{23}$ demonstrated that the results on efficiency begin to appear as of the third year of adherence to the program, that is, a period of experience and adaptation is required for governance of the expansion of service technology delivery in PHC to show results;

4) The expansion, training, and coordination of the family health teams during the years of adherence to the "Pacto pela Saúde" program provided greater monitoring of families over time. These factors resulted in health promotion actions and, consequently, lower rates of morbidity and mortality.

Therefore, it can be assumed that action-planning and coordination within municipal health systems have improved since joining the "Pacto pela Saúde" program. The combination of committed management with results and PHC investments in the municipal health system governance culminated, on the one hand, in the promotion of health in the municipalities and, on the other hand, in the decline of their HVI.

Through the construction of a SCM of the health system of Brazilian municipalities, this study also evidenced the different channels that affect health outcomes. This finding suggests that a health policy should consider different dimensions to ensure its efficiency. It is understood that management is only one channel among many others, that is, management efficiency is necessary, but not sufficient in itself.

It is further worth noting that the Pearl's ${ }^{24}$ methodology has proved to be a useful tool in this study to evaluate public policies. Moreover, the Pearl's model is shown as relevant for evaluating policies not only by the back-door criterion itself, but also by providing a new methodology to construct structural causal models combined with graphical analysis. These analyses, in turn, facilitate understanding the broader scope of a policy as well as which channels can impact on the results of interest. To sum up, the use of the Pearl's method in this study contributed to a more comprehensive analysis of the effects of the "Pacto pela Saúde" program on health outcomes; therefore, its use in future analysis of public policies is recommended. 


\section{REFERENCES}

1. Deaton A. Health, inequality, and economic development. J Econ Lit. 2003;41(1):113-58. http://dx.doi. org/10.1257/jel.41.1.113.

2. Lopez-Casasnovas G, Rivera B, Currais L, editors. Health and economic growth: findings and policy implications. Cambridge: MIT Press; 2005. http://dx.doi.org/10.7551/mitpress/3451.001.0001.

3. Organisation for Economic Co-operation and Development. Value for money in health spending. Paris: OECD Publishing; 2010. (OECD Health Policy Studies).

4. World Health Organization. The world health report 2000: health systems - improving performance. Geneva:WHO; 2000.

5. World Health Organization. The world health report 2008: primary health care - now more than ever. Geneva:WHO; 2008.

6. Heckman JJ, Mosso S. The economics of human development and social mobility. NBER Working Pap Ser. 2014;1(19925):1-73.

7. Schultz TW. Investment in human capital. Am Econ Rev. 1961;51(1):1-17.

8. McKeown RE. The epidemiologic transition: changing patterns of mortality and population dynamics. Am J Lifestyle Med. 2009;1(3 Suppl.):19S-26S. http://dx.doi.org/10.1177/1559827609335350. PMid:20161566.

9. Xu K, Saksena P, Holly A. The determinants of health expenditure: a country-level panel data analysis. WHO Working Pap. 2011;1(1):1-26.

10. Organisation for Economic Co-operation and Development. Health care systems: efficiency and policy settings. Paris: OECD Publishing; 2010.

11. Starfield B, Shi L. Policy relevant determinants of health: an international perspective. Health Policy. 2002;60(3):201-18. http://dx.doi.org/10.1016/S0168-8510(01)00208-1. PMid:11965331.

12. Solla J, Chioro A. Atenção ambulatorial especializada. In: Giovanella L, Escorel S, Lobato LVC, editors. Políticas e sistema de saúde no Brasil. 2. ed. Rio de Janeiro: Fiocruz; 2012.

13. Starfield B. Atenção primária: equilíbrio entre necessidades de saúde, serviços e tecnologia. Brasília: UNESCO, Ministério da Saúde; 2002.

14. Paim J. Modelos de atenção à saúde no Brasil. In: Giovanella L, Escorel S, Lobato LVC, editors. Políticas e sistema de saúde no Brasil. 2. ed. Rio de Janeiro: Fiocruz; 2012.

15. Scott A. Economics of general practice. In: Culyer AJ, Newhouse JP, editors. Handbook of health economics. Amsterdan: Elsevier; 2000. (vol. 1A).

16. Rajkumar AS, Swaroop V. Public spending and outcomes: does governance matter? J Dev Econ. 2008;86(1):96-111. http://dx.doi.org/10.1016/j.jdeveco.2007.08.003.

17. Organisation for Economic Co-operation and Development. Fiscal sustainability of health systems: bridging health and finance perspectives. Paris: OECD Publishing; 2015.

18. Saltman RB, Bankauskaite V, Vrangbaek K, editors. Decentralization in health care: strategies and outcomes. New York: McGraw-Hill; 2007. (European Observatory on Health Systems and Policies Series).

19. Oates WE. Toward a second-generation theory of fiscal federalism. Journal of International Tax and Public Finance. 2005;12(1):349-73. http://dx.doi.org/10.1007/s10797-005-1619-9.

20. Asfaw A, Frohberg K, James KS, Jutting J. Modeling the impact of fiscal decentralization on health outcomes: empirical evidence from India. ZEF Discuss Pap Dev Policy. 2004;1(87):1-29.

21. Channa A, Faguet J. Decentralization of health and education in developing countries: a quality-adjusted review of the empirical literature. Econ Organ Public Policy Discuss Pap. 2012;1(38):1-46.

22. Brasil. Ministério da Saúde. Caderno de diretrizes, objetivos, metas e indicadores: 2013-2015. 2. ed. Brasília: Ministério da Saúde; 2014.

23. Kroth DC, Guimarães RRM. Avaliação do efeito causal do Pacto pela Saúde sobre indicador de eficiência da gestão da política municipal de saúde (2006-2013). In: Anais do 45 Encontro Nacional de Economia; 2017; Natal (RN): ANPEC; 2017.

24. Pearl J. Causality: models, reasoning, and inference. 2nd ed. New York: Cambridge University Press; 2009. http://dx.doi.org/10.1017/СBO9780511803161.

25. Lechner M. Identification and estimation of causal effects of multiple treatments under conditional Independence assumption. In: Lechner M, Pfeiffer F, editors. Econometric evaluation of labour market policies. Heidelberg: Physica; 2001 http://dx.doi.org/10.1007/978-3-642-57615-7_3. 
26. Imbens GW. The role of the propensity score in estimating dose-response functions. Biometrika. 2000;87(3):706-10. http://dx.doi.org/10.1093/biomet/87.3.706.

27. Gertler PJ, Martinez S, Premand P, Rawlings LB, Vermeersch CMJ. Impact evaluation in practice. 2. ed. Washington, DC: The World Bank; 2016. http://dx.doi.org/10.1596/978-1-4648-0779-4.

28. Glennerster R, Takavarasha K. Running randomized evaluations: a practical guide. Princeton: Princeton University Press; 2013. http://dx.doi.org/10.2307/j.ctt4cgd52.

29. Jolliffe IT. Principal component analysis. 2nd ed. New York: Springer; 2002.

30. Wilkinson R, Marmot M, editors. Social determinants of health: the solid facts. 2nd ed. Geneva: World Health Organization; 2003.

31. Dahlgren G, Whitehead M. Policies and strategies to promote social equity in health: background document to WHO - Strategy paper for Europe. Stockholm: Institute for Futures Studies; 1991.

32. Grossman M. On the concept of health capital and the demand for health. J Polit Econ. 1973;80(1):223-55.

33. Lalonde M. A new perspective on the health of Canadians: a working document. Government of Canada; 1974.

34. Morgan SL, Winship C. Counterfactuals and causal inference: methods and principles for social research. 2nd ed. New York: Cambridge University Press; 2015.

35. Guardabascio B, Ventura M. Estimating the dose-response function through the GLM approach. Munich Personal Repec Archive. 2013;1(45013):1-31.

36. Hone T, Rasella D, Barreto M, Atun R, Majeed A, Millett C. Large reductions in amenable mortality associated with Brazil's primary care expansion and strong health governance. Health Aff. 2017;36(1):149-58. http:// dx.doi.org/10.1377/hlthaff.2016.0966. PMid:28069858. 